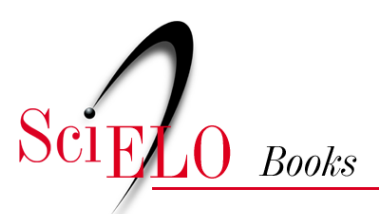

\title{
A construção do espaço rural nas colônias de imigrantes do sul do Brasil
}

\author{
Manoel P. R. Teixeira dos Santos
}

\section{SciELO Books / SciELO Livros / SciELO Libros}

SANTOS, M.P.R.T. A construção do espaço rural nas colônias de imigrantes do sul do Brasil. In: GERHARDT, M., NODARI, E.S., and MORETTO, S.P., eds. História ambiental e migrações: diálogos [online]. São Leopoldo: Oikos; editora UFFS, 2017, pp. 63-80. ISBN: 978-85-64905-68-9. https://doi.org/10.7476/9788564905689.0005.

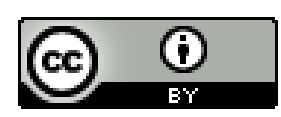

All the contents of this work, except where otherwise noted, is licensed under a Creative Commons Attribution 4.0 International license.

Todo o conteúdo deste trabalho, exceto quando houver ressalva, é publicado sob a licença Creative Commons Atribição 4.0.

Todo el contenido de esta obra, excepto donde se indique lo contrario, está bajo licencia de la licencia $\underline{\text { Creative Commons }}$ Reconocimento 4.0. 


\title{
A construção do espaço rural nas colônias de imigrantes do sul do Brasil
}

\author{
Manoel P. R. Teixeira dos Santos
}

\section{Introdução}

A partir do século XIX, o sul do Brasil recebeu grandes levas de imigrantes europeus com destino às colônias fundadas na região. Este processo de colonização promoveu a ocupação de extensas áreas florestais consideradas vazios demográficos pelo poder público brasileiro. Considerando isso, este trabalho tem por objetivo compreender a construção do espaço rural nas colônias de imigrantes no Brasil meridional, com destaque para Colônia Blumenau, fundada em 1850, na então província de Santa Catarina. A Mata Pluvial Atlântica era, portanto, o espaço a ser ocupado pelos imigrantes através do estabelecimento de pequenas propriedades dedicadas à policultura de subsistência e ao abastecimento do mercado interno. Este era um modelo de ocupação que contrastava significativamente com a estrutura fundiária brasileira, baseada no latifúndio monocultor. Neste sentido, procuramos identificar a transformação ambiental da região através da compreensão do processo de privatização das terras florestais e da identificação dos modelos de ocupação, colonização e propriedade adotados. Para isso, buscamos analisar mapas e plantas coloniais, assim como relacionar dados sobre o crescimento do número de proprietários rurais com a expansão das áreas de cultivo.

A primeira colônia alemã de Santa Catarina foi São Pedro de Alcântara, fundada em 1829 nas proximidades de Nossa Senhora do Desterro, atual Florianópolis. No entanto, a intensificação da colonização ocorreu somente a partir da segunda metade do século XIX como a fundação de colônias como Blumenau, Itajaí e Príncipe Dom Pedro (Brusque), no vale do Itajaí, e Dona Francisca no norte do estado. Ao refletir sobre o sentido do processo de colonização em Santa Catarina, Paulo Lago afirmou:

Os ambientes iniciais de assentamentos foram vales da Vertente Atlântica. O processo de ocupação de espaços e a correspondente aplicação de técnicas 
nas relações homem/meio balizaram-se por um rumo de interiorização LesteOeste em direção às linhas divisoras entre a vertente Atlântica e as bacias dos rios Uruguai e Iguaçu (1988, p. 88).

A Mata Pluvial Atlântica era, portanto, o espaço a ser ocupado pelos imigrantes através do estabelecimento de pequenas propriedades dedicadas à policultura de subsistência e abastecimento do mercado interno. Este era um modelo de ocupação que contrastava significativamente com a estrutura fundiária brasileira baseada no latifúndio monocultor. A visão do Estado brasileiro era promover a ocupação do que chamava de "vazios demográficos", no entanto, a instalação de "colônias" em terras antes devolutas ou adquiridas para fins colonizadores nem sempre se encontravam de fato demograficamente vazias. "Remanescentes pré-cabralinos e posseiros luso-brasileiros, com ou sem títulos legitimados de propriedade, frequentemente miscigenando-se com os primeiros, eram comuns, ainda que muito rarefeitos" (LAGO, 1988, p. 88).

Os contatos entre indígenas e colonos foram marcados pelo "estranhamento". Desamparados pela justiça, os indígenas eram considerados intrusos em sua própria terra. Da mesma forma, os colonos que adquiriam seus lotes coloniais eram vistos pelos indígenas como os verdadeiros invasores. A participação dos lavradores nacionais (caboclos) neste contato foi pouco registrada em relatos e documentos oficiais. Entretanto, a sua presença e influência no modo de vida dos colonos pode ser percebida em aspectos da vida colonial como o modelo de construção das primeiras residências e pelas técnicas e culturas agrícolas adotadas pelos imigrantes.

A marcha das frentes de colonização, no Leste ou no Oeste de Santa Catari-
na, sempre implicava na supressão de grupos ou pessoas que precediam,
como habitantes sem amparo jurídico, os novos donos das terras.
Os índios e brancos caboclizados pelo isolamento social não representaram
resistências fortes aos avanços colonizadores, à exceção do ocorrido no Pla-
nalto, no interior de uma vasta região em que a questão dominante e central
residia na própria definição de competência política (LAGO, 1988, p. 89).

\section{Privatização das Terras Florestais}

O processo de ocupação das florestas através do estabelecimento de colônias de imigrantes europeus proporcionou mudanças físicas evidentes no espaço regional, mas ao lado delas também estiveram presentes as transformações culturais e sociais. Entre os diversos aspectos significativos des- 
tas mudanças está a valorização da propriedade da terra para fins comerciais. A privatização das terras florestais consolidou a ocupação deste espaço pelo colonizador europeu assim como acelerou a exclusão de índios e lavradores nacionais. Segundo Zarth:

A privatização das terras florestais atingiu os lavradores nacionais que tinham como alternativa a ocupação das terras devolutas, onde poderiam sobreviver como camponeses independentes. Deste modo, na década de 1850 mais ou menos, deu-se início ao fechamento do livre acesso à terra para os lavradores pobres. A situação era curiosa: em meio a imensas áreas ociosas, os lavradores queixavam-se de não terem terras para trabalhar, eram semterra em meio à abundância de solos virgens (2002, p. 83).

A Lei de Terras de 1850 permitiu, em muitas províncias do Império, um grande aumento na concentração das áreas cultiváveis nas mãos de uma elite latifundiária. Entretanto, no sul do país, a mesma lei estimulou que enormes áreas de solo virgem fossem objeto de grandes negócios imobiliários com a fundação de empreendimentos coloniais particulares e a comercialização de lotes aos imigrantes.

A colonização, como empreendimento privado ou sob o gerenciamento do poder público, procurava assegurar retorno de investimentos mediante esquemas de comercialização de lotes de terras.

As grandes glebas eram adquiridas por empresas ou particulares sob critérios semelhantes de pagamento e, em muitos exemplos, como prestação de serviços. Empreiteiras que abriam estradas de ferro ou rodovias foram, por muitos exemplos, transformadas em empresas de colonização loteando, em geral, faixas de terras linearmente dispostas ao longo das vias abertas (LAGO, 1988, p. 204).

No caso das empresas privadas, o passo inicial era a organização técnica e financeira do empreendimento. Em diversos casos essas empresas colonizadoras valiam-se de recursos oriundos de grupos capitalistas internacionais. Posteriormente, as atenções eram dedicadas às operações burocráticas junto aos governos para definição das obrigações, a indicação e a demarcação das terras para colonização. A etapa seguinte consistia na busca pelos futuros imigrantes através de campanhas publicitárias e agentes de emigração. Neste momento surgiam promessas nem sempre cumpridas pela própria empresa ou pelos setores oficiais.

A colonização era um negócio. Os investidores avaliavam os riscos e acreditavam no sucesso, baseados em concepções e planos elaborados visando aumentar o retorno dos investimentos. 
Jamais encararam a experiência colonizadora como empreendimento aventureiro. Elas partiram do pressuposto de que as possibilidades de acerto eram consideráveis, o que colocava a colonização como uma hipótese de negócio rentável, pelo menos a longo prazo (LAGO, 1988, p. 204).

No caso da Colônia Blumenau, o processo de colonização ocorreu a partir do planejamento de seu diretor ${ }^{1}$, seguindo o que estava determinado pelo regulamento das coloniais estatais. Segundo José Ferreira da Silva, o modelo adotado "era o da imigração espontânea, vindo colonos ordinariamente, às suas próprias custas e só em casos especiais era-lhes adiantada a passagem pela direção da Colônia" (1972, p. 56).

Entre a chegada na colônia e a colheita das primeiras lavouras existia uma longa jornada, realizada, geralmente, com grandes sacrifícios. De uma forma geral, eram os pobres que emigravam da Europa, e, por isso, a aquisição dos lotes era realizada com suas poucas economias. Para sobrevivência nos primeiros meses existia um sistema de auxilio e também o parcelamento do lote adquirido.

A direção da colônia adiantava a cada colono, inclusive aos membros de sua família, auxílio de 100 dias, por meio de diárias no valor total de $20 \$ 000$ a $25 \$ 000$. Após este período de 100 dias, o colono já deveria ter condições suficientes para manutenção, através do próprio trabalho. [...] O fornecimento de alimentícios era feito aos imigrantes, a crédito, estando os mesmos obrigados a restituir o respectivo valor, após as primeiras colheitas, ficando suas terras alienadas até a devolução (HILLESHEIM, 2000, p. 41).

Os colonos recém-chegados não possuíam condições de produzir, ao menos nos primeiros três meses após o recebimento do lote. De uma forma geral, até os seis meses iniciais ainda dependiam quase que exclusivamente do auxílio da direção ou dos serviços prestados a terceiros.

Uma das grandes dificuldades na relação colono/colonizadora residia nas normas das relações contratuais. As vendas dos lotes se efetuavam, geralmente, com o pagamento a longo prazo, com parcelas e juros adicionais. Ficavam presos à terra até a quitação das dívidas. Para contribuir com o pagamento era comum que os colonos atuassem na prestação de serviços, como abrir estradas e picadas para empresas e para os governos.

Em sua obra sobre atuação da Sociedade Colonizadora Hanseática em Santa Catarina, Klaus Ricther apontou o que entendia como os princi-

\footnotetext{
${ }^{1}$ Neste caso, cabe destacar que a Colônia Blumenau foi transferida do Dr. Hermann Blumenau para o governo imperial em 1860.
} 
pais problemas do sistema de venda dos lotes aplicados no Brasil. Para ele, o modelo possuía três graves defeitos:

Primeiro, os lotes de na média 25 hectares eram grandes demais para que uma família de colonos pudesse cultivá-lo, sendo que nos primeiros dez anos em geral não mais de $20 \%$ da área seriam cultivados, enquanto que por volta de $80 \%$ permaneceriam incultos, embora o colono tivesse que pagar prestação e juros por ele também.

Segundo, a classificação de acordo com a qualidade das terras estava sendo feita de maneira arbitrária, visando antes de tudo classificar um máximo de lotes na primeira classe de 44 mil-réis, a fim de garantir à Sociedade melhor receita.

Terceiro, as condições de pagamento, sobretudo o curto prazo e os juros elevados, não correspondiam às possibilidades financeiras dos colonos. Consequentemente, os recém-chegados estavam sendo prejudicados no sentido de terem que empregar capital demais dos seus poucos recursos para pagar pelos seus lotes, assim que a economia da colônia Hansa não conseguia crescer tão rápida como seria de se esperar (RICHTER, 1986, p. 86).

O primeiro defeito apontado por Richter é bastante controverso. Os lotes rurais de 25 hectares eram realmente subaproveitados nos primeiros anos e isso os tornava realmente caros. No entanto, as técnicas agrícolas adotadas nas regiões coloniais eram baseadas na derrubada e queimada e na mudança frequente das áreas destinadas ao plantio, o que acabava exigindo de fato maiores extensões de terras. $\mathrm{O}$ uso deste sistema nas pequenas propriedades coloniais foi motivo de grandes críticas de especialistas.

As outras críticas de Richter estavam direcionadas aos interesses comerciais das companhias de colonização. A especulação imobiliária através da privatização das terras florestais ocorreu através da participação de diversas companhias colonizadoras nacionais e estrangeiras. Os modelos de colonização e ocupação dos espaços adotados nos diversos núcleos coloniais eram muito parecidos e acabaram por determinar características marcantes da vida rural colonial.

\section{Modelos de colonização e ocupação}

O estabelecimento das colônias era condicionado à demarcação dos espaços destinados aos lotes rurais e a áreas prevista para sede, fragmentada em lotes urbanos. Segundo Paulo Lago:

A concepção deste esquema de fixação de grupos humanos foi, pioneiramente, germânica. O modelo se tornou repetitivo, com variações tanto nas 
proporções entre "lotes urbanos" e "lotes rurais" quanto nas próprias dimensões de cada unidade fundiária. Influências específicas dos sítios de assentamentos e outras relacionadas com interesses das empresas que gerenciavam a colonização bem como com suas dimensões influíram na caracterização particularizada das colônias (1988, p. 205).

$\mathrm{Na}$ demarcação dos lotes coloniais, a participação dos agrimensores tornou-se fundamental. A medição de lotes rurais e urbanos, abertura de picadas, medição de frente e "linhas laterais e fundos, bem como a conservação dos diferentes marcos" eram de responsabilidade do agrimensor Dentre os terrenos medidos, cujo tamanho médio era de 25 hectares $^{2}$, a distribuição era feita a livre escolha.

As dificuldades preliminares de demarcação e partilha dos lotes eram muito grandes. Para Paulo Lago, "os espaços eram virgens, frequentemente inacessíveis. Nada facilitava os trabalhos exaustivos dos agrimensores, a não ser a fértil disposição de referências como as linhas de umidade dos fluxos e a por vezes enganosa disposição das linhas de cumiadas" (LAGO, 1988, p. 208).

A importância e complexidade do processo de colonização fizeram com que setores administrativos fossem especialmente criados para as operações de cadastramento de propriedades, como a Companhia de Terras e Colonização vinculada ao Ministério da Agricultura. A colonização, determinou, portanto, o retalhamento demarcatório de grandes extensões de terras em milhares de pequenas unidades. Esta ação ocorreu através da aplicação de técnicas de agrimensura para se estabelecer precisão de limites e, desta forma, evitar maiores conflitos. Este tipo de ação contribuía para evitar problemas comuns nas áreas de terras adquiridas a partir da concessão de sesmarias ${ }^{3}$.

\footnotetext{
${ }^{2} \mathrm{O}$ tamanho médio dos lotes sofreu transformações ao longo do processo de colonização. A fundação da colônia de São Leopoldo no Rio grande do Sul, em 1824, proporcionou a concessão de propriedades com até 75 hectares de superfície. No entanto, este modelo não foi adotado por muito tempo. Após a Lei de Terras, em 1850, quando a concessão foi substituída pela compra, o tamanho médio dos lotes foi reduzido primeiro para 50 hectares e, posteriormente, para o típico minifúndio de 25 a 30 hectares. Em Blumenau, por exemplo, a maior parte dos seus primeiros, lotes divididos em 28 de agosto de 1852 pelo Dr. Blumenau, possuía por volta de 35 hectares, mas, em sua sequência, os lotes passaram a girar entre 25 e 30 hectares.

${ }^{3}$ Distribuídas no Brasil através de concessão desde 1530 e extintas a partir da Lei de Terras de 1850 .
} 
Figura 1: Modelo de colonização

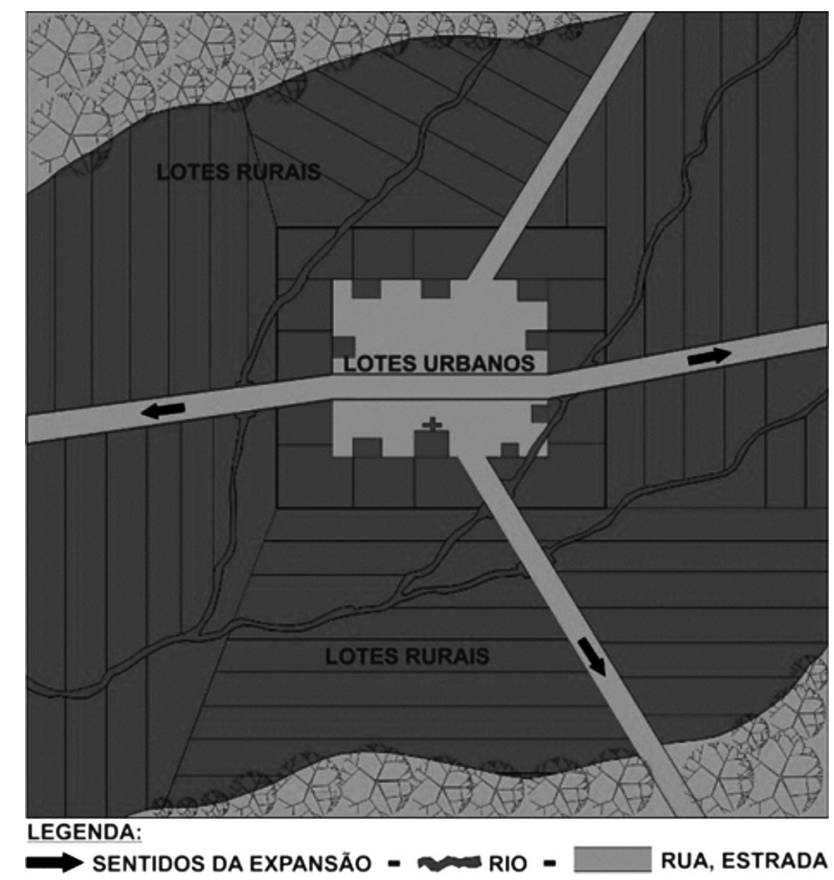

Fonte: Adaptado de LAGO, Paulo Fernando. Gente da Terra Catarinense-Desenvolvimento e Educação Ambiental. Florianópolis: Ed. Da UFSC/FCC Edições /Ed. Lunardelli/UDESC, 1988

As condições geográficas e a forma de distribuição dos lotes, indicadas na figura acima, impediram que houvesse demarcação de "propriedades rurais" com dimensões homogêneas. Entre os aspectos unificadores estava a disposição longitudinal relacionada às vias de acesso (picadas, estradas, etc.) e a existência de cursos d'água. Este formato alongado fez com que, nas colônias fundadas em vales estreitos, os lotes tivessem seus fundos no alto dos morros. Desta forma, as plantações, iniciadas nas várzeas avançavam pelas encostas chegando até uma pequena reserva de mata no alto das colinas. Os morros não eram totalmente desmatados, permitindo uma reserva de madeira e lenha para propriedade. Estas paisagens podem ser identificadas até hoje nas regiões rurais do vale do Itajaí.

Esta forma de distribuição das propriedades rurais transformou-se numa das características mais marcantes desta colonização no sul do Brasil. Além de proporcionar a todos os colonos lotes com características semelhantes e providos de água, mata e ao menos mínimas condições de acesso (picadas, 
estradas, etc.), este modelo também permitia uma maior aproximação física entre as casas dos colonos. Para Giralda Seyferth, o fato da propriedade rural também ser chamada de colônia é carregado de significado. Segundo ela, "a colônia (pequena propriedade) é concebida como um microcosmo autossuficiente na visão dos imigrantes e seus descendentes" (SEYFERTH, 1990, p. 25). A pequena propriedade colonial foi assumida, desde o início, como a unidade básica do sistema colonial. As práticas rurais adotadas pelos imigrantes eram demarcadas pelos limites de cada lote colonial.

A forma de distribuição dos lotes coloniais também pode ser entendida através dos mapas de ocupação da colônia Blumenau publicados, eventualmente, nos relatórios coloniais. Através deles observamos mais uma vez a demarcação dos lotes de forma retangular com sentido longitudinal em relação a estradas e rios.

Figura 2: Planta da Colônia Blumenau - 1864

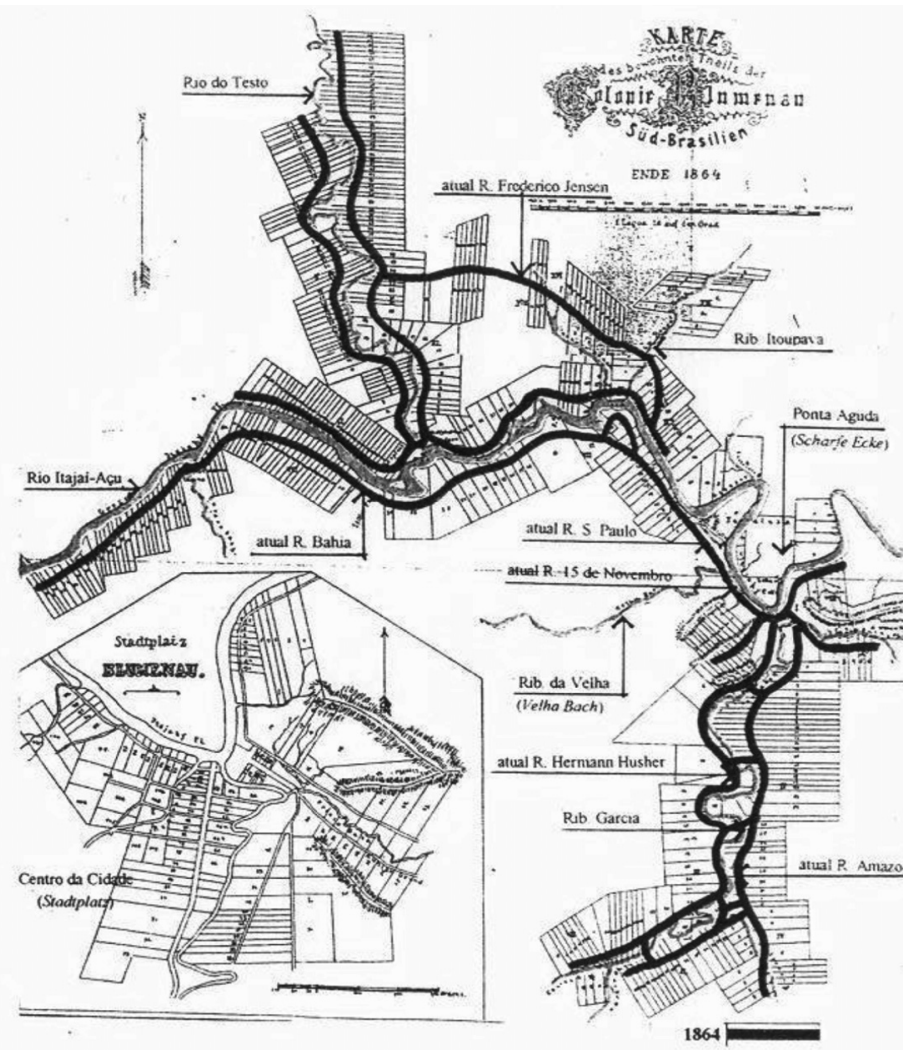

Fonte: Acervo do Arquivo Histórico José Ferreira da Silva 
Figura 3: Planta da Colônia Blumenau - 1872

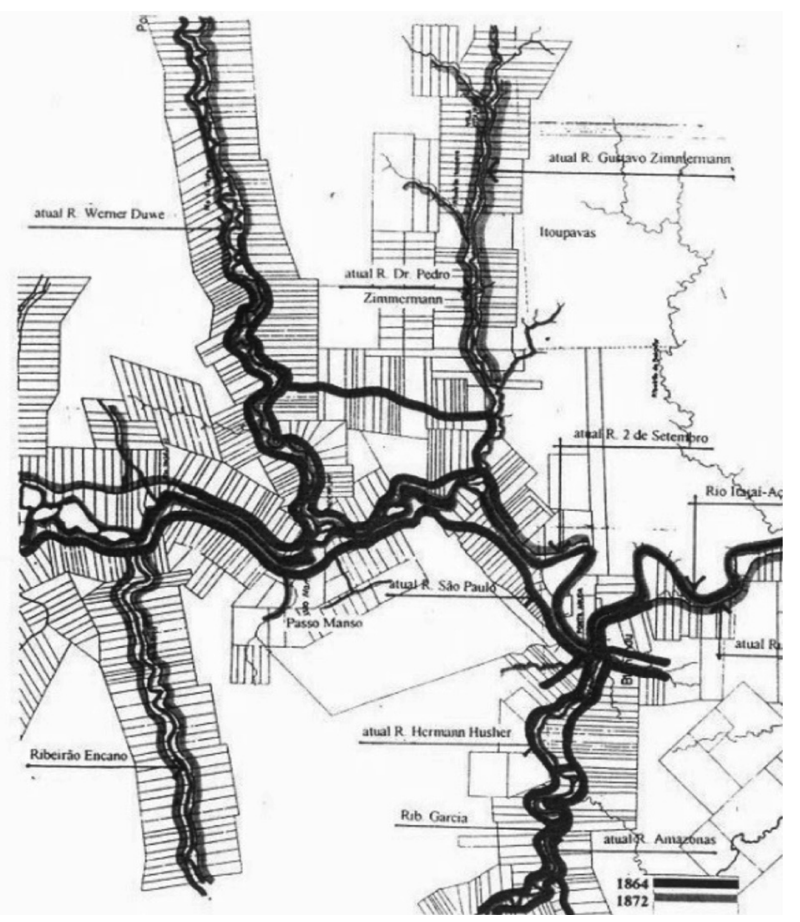

Fonte: Acervo do Arquivo Histórico José Ferreira da Silva

Os mapas acima também nos auxiliam a identificar o sentido da expansão territorial e da ocupação espacial da colônia, assim como aponta para as transformações ambientais desencadeadas por este processo. No curto intervalo entre os dois mapas apresentados (1864 e 1872), registra-se um grande aumento na demarcação e comercialização dos lotes coloniais. Trata-se de um período de maior desenvolvimento da colônia, já sob o controle do Império e com um aumento significativo dos recursos investidos.

Com objetivo de avançar na compreensão da ocupação espacial das áreas florestais onde foi instalada a colônia Blumenau, buscamos valiosas informações presentes nos relatórios e mapas estatísticos produzidos pela direção da colônia entre 1861 e $1880 .{ }^{4}$ Entre os dados mais relevantes para esta análise estão a expansão das áreas de cultivo e pastagem aliadas ao número de proprietários rurais na colônia.

\footnotetext{
${ }^{4}$ Trata-se do período entre a aquisição da colônia pelo governo imperial e a emancipação de Blumenau.
} 
Tabela 1: Dados da ocupação espacial da Colônia Blumenau (1861-1880)

\begin{tabular}{|c|c|c|c|}
\hline Ano & Proprietários & Área Cultivada (ha) & Área cultivada pasto (ha) \\
\hline 1861 & 279 & 279,27 & 290,4 \\
\hline 1862 & 362 & 233,8 & 314,6 \\
\hline 1863 & 441 & 705,19 & 377,52 \\
\hline 1864 & 476 & $1.013,5$ & 580,8 \\
\hline 1865 & 537 & $1.222,47$ & 620,8 \\
\hline 1866 & 574 & 1.215 & 824,49 \\
\hline 1867 & 808 & $1.593,2$ & 981,31 \\
\hline 1868 & 1.083 & $2.198,2$ & $1.344,31$ \\
\hline 1869 & 1.400 & $2.379,2$ & $1.519,85$ \\
\hline 1870 & 1.423 & $2.854,2$ & $1.810,28$ \\
\hline 1871 & 1.427 & 3.416 & 1.839 \\
\hline 1872 & 1.200 & 3.570 & 1.853 \\
\hline 1873 & 1.282 & 3.672 & 1.898 \\
\hline 1874 & 1.388 & 4.752 & n.e \\
\hline 1875 & n.e & n.e & 5.547 \\
\hline 1876 & 2.345 & n.e & $5.982,9$ \\
\hline 1877 & 2.488 & 10.200 & $6.059,05$ \\
\hline 1878 & 2.727 & 11.000 & $6.737,34$ \\
\hline 1879 & 2.897 & 11.140 & \\
\hline 1880 & 2.948 & $12.388,2$ & \\
\hline
\end{tabular}

n.e $=$ dados não existentes

Fonte: HILLESHEIM, Anselmo Antônio. O crescimento do mercado interno numa colônia do Império - O caso de Blumenau: 1850-1880. (Parte 1). In: Revista Blumenau em Cadernos - Tomo XLI - n. 5, maio, 2000.

HILLESHEIM, Anselmo Antônio. O crescimento do mercado interno numa colônia do Império - O caso de Blumenau: 1850-1880. (Parte 3). In: Revista Blumenau em Cadernos Tomo XLI - n. 7, julho, 2000.

Através da tabela acima, identificamos em números as áreas (em hectares) ocupadas pelos cultivos e pastos. Para facilitar a interpretação destes dados, elaboramos alguns gráficos que nos permitem compreender melhor a evolução do número de proprietários e das áreas de pasto e cultivo no intervalo analisado. 
Gráfico 1: Expansão da ocupação espacial da Colônia Blumenau (18611880)

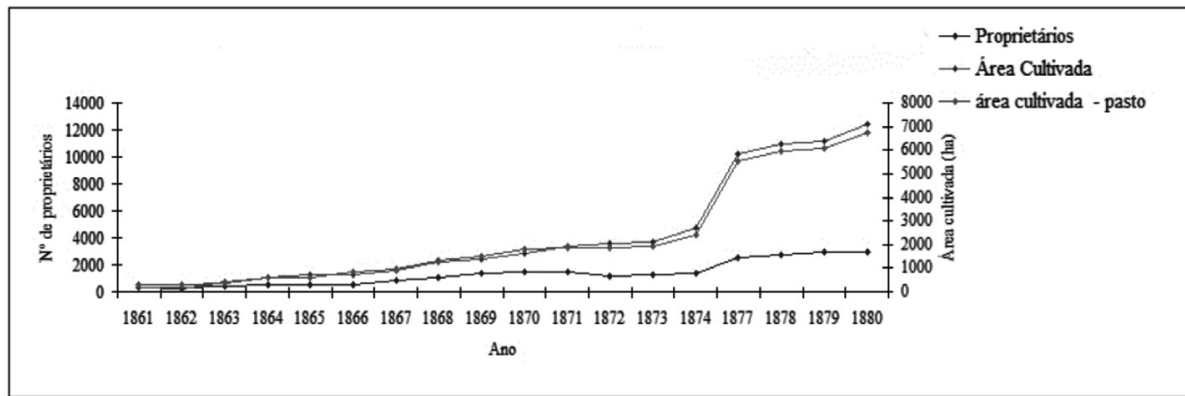

Fontes: HILLESHEIM, Anselmo Antônio. O crescimento do mercado interno numa colônia do Império - O caso de Blumenau: 1850-1880. (Parte1). In: Revista Blumenau em Cadernos - Tomo XLI - n. 5, maio, 2000.

HILLESHEIM, Anselmo Antônio. O crescimento do mercado interno numa colônia do Império - O caso de Blumenau: 1850-1880. (Parte 3). In: Revista Blumenau em Cadernos Tomo XLI - n. 7, julho, 2000.

Entre as possíveis interpretações do gráfico acima está um dos aspectos fundamentais para esta pesquisa, a identificação da progressiva transformação das áreas florestais em espaços de produção rural pelos colonos. Observamos que a partir dos anos 1870 ocorre uma progressiva separação dos eixos que identificam o número de proprietários com os outros dois que representam os cultivos e as pastagens. Portanto, fica evidente que os métodos de cultivo baseados na derrubada e na queimada aceleravam a derrubada da mata e o abandono por alguns anos das terras em desgaste. Os dois gráficos apresentados a seguir indicam uma média de crescimento das áreas de cultivo e de pasto por cada proprietário. 
Gráfico 2: Área cultivada por proprietário (HA)

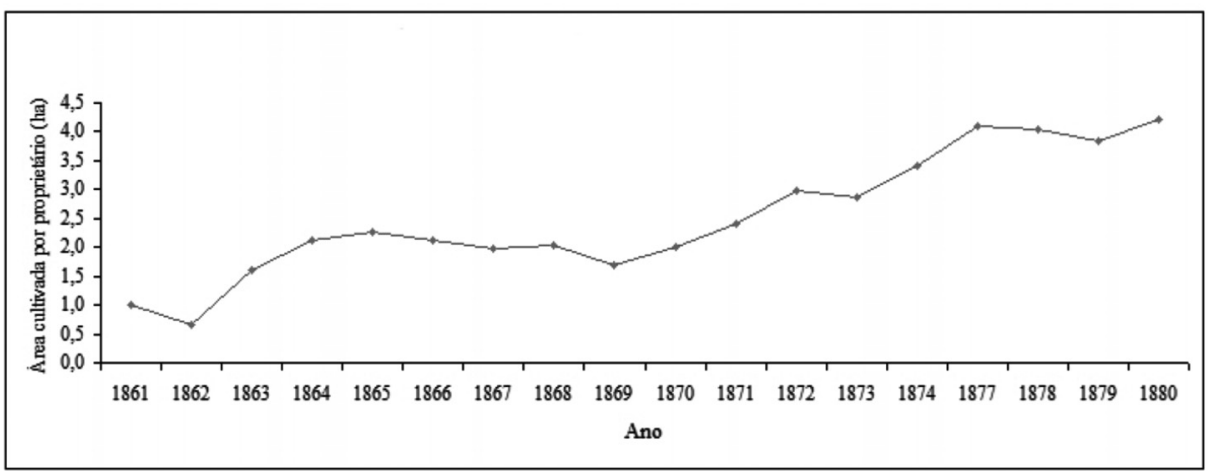

Fontes: HILLESHEIM, Anselmo Antônio. O crescimento do mercado interno numa colônia do Império - O caso de Blumenau: 1850-1880. (Parte1). In: Revista Blumenau em Cadernos - Tomo XLI - n. 5, maio, 2000.

HILLESHEIM, Anselmo Antônio. O crescimento do mercado interno numa colônia do Império - O caso de Blumenau: 1850-1880. (Parte 3). In: Revista Blumenau em Cadernos Tomo XLI - n. 7, julho, 2000.

Gráfico 3: Área cultivada (pasto) por proprietário

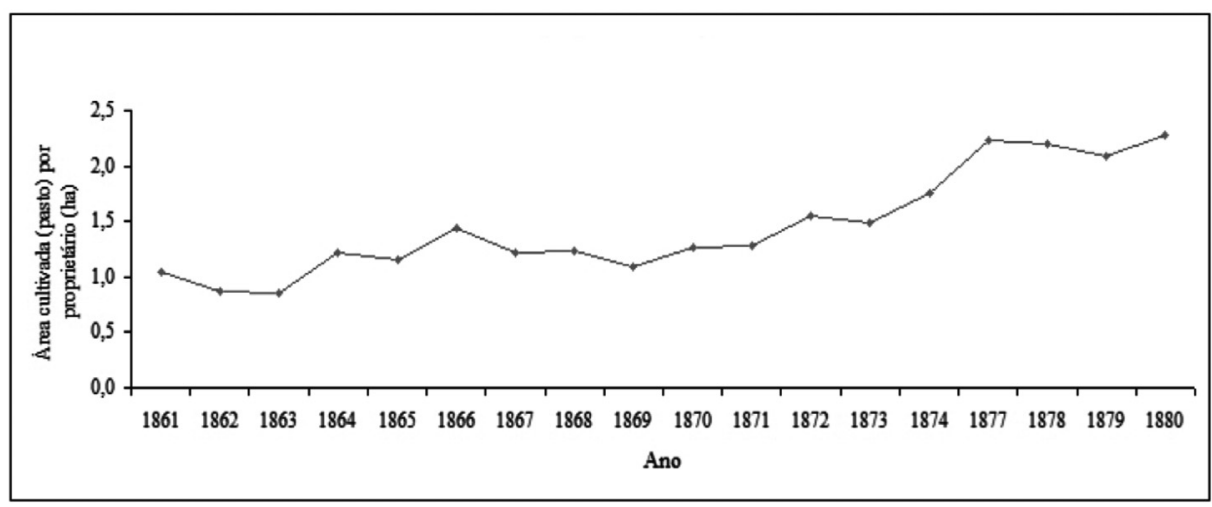

Fontes: HILLESHEIM, Anselmo Antônio. O crescimento do mercado interno numa colônia do Império - O caso de Blumenau: 1850-1880. (Parte1). In: Revista Blumenau em Cadernos - Tomo XLI - n. 5, maio, 2000.

HILLESHEIM, Anselmo Antônio. O crescimento do mercado interno numa colônia do Império - O caso de Blumenau: 1850-1880. (Parte 3). In: Revista Blumenau em Cadernos Tomo XLI - n. 7, julho, 2000. 
Observamos mais uma vez que este crescimento foi progressivo. As pequenas variações apresentadas poderiam ser justificadas principalmente pelos fatores climáticos que, por diversas vezes, afetaram os blumenauenses em sua história. As chuvas excessivas e as geadas nos invernos mais rigorosos foram frequentemente registradas nos relatos e documentos oficiais.

\section{Estrutura da pequena propriedade colonial}

A fundação de colônias nas matas fechadas da então Província de Santa Catarina modificou muito a paisagem destas regiões. É evidente que a derrubada de grandes áreas florestais não foi "privilégio" destes que lá habitaram. Enormes porções de florestas nativas foram destruídas em todo território brasileiro, na maior parte dos casos feita de forma irracional pelos grandes latifundiários, visando a exploração em grande escala nas monoculturas de café (Sudeste) e cana-de-açúcar (Nordeste) ${ }^{5}$ e, sobretudo, o crescimento desenfreado das grandes cidades.

Uma descrição da atual formação geográfica da região onde se encontram as cidades de Blumenau, Brusque e Indaial, diferiria em muito da descrição feita por colonos e viajantes durante a segunda metade do século XIX. As razões que levaram a estas mudanças estavam automaticamente ligadas às necessidades das famílias que para ali se transferiram. A mata e a lavoura não poderiam ocupar o mesmo espaço, e a roça era inicialmente seu único meio de subsistência.

Esta visão da floresta como adversária está relacionada às principais visões de desenvolvimento presentes em nossa sociedade ao longo da história. Keith Thomas, em sua análise sobre as relações do ser humano com o meio natural, assim descreveu esta relação:

Há apenas poucos séculos atrás, a mera ideia de resistir à agricultura, ao invés de estimulá-la, parecia ininteligível. Como teria progredido a civilização sem a limpeza das florestas, o cultivo do solo e a conversão da paisagem agreste em terra colonizada pelo homem? Os reis e grandes proprietários podiam reservar florestas e parques para caça e extração de madeira, mas na Inglaterra dos Tudor a preservação artificial dos cumes incultos teria parecido tão absurda como a criação de santuários para pássaros e animais selvagens que não podiam ser comidos ou caçados. A tarefa do homem nas pala-

\footnotetext{
${ }^{5}$ Sobre este assunto ver mais em: DEAN, Warren. A Ferro e Fogo: a história e a devastação da Mata Atlântica brasileira. São Paulo: Companhia das Letras, 1996.
} 
vras do Gênesis (I.28), era "encher a terra e submetê-la": derrubar matas, lavrar o solo, eliminar predadores, matar insetos nocivos, arrancar fetos, drenar pântanos. A agricultura estava para a terra como o cozimento para a carne crua. Convertia natureza em cultura. Terra não cultivada significava homens incultos. E quando os ingleses seiscentistas se mudaram para Massachussets, parte de sua argumentação em defesa da ocupação dos territórios indígenas foi que aqueles que por si mesmos não submetiam e cultivavam a terra não tinham direito de impedir que outros o fizessem (2001, p. 17).

Ao adquirir um lote colonial, o primeiro passo, após a demarcação, era a construção de uma moradia onde fosse possível ao imigrante alojar-se com sua família. Neste momento, reconhecendo as difíceis circunstâncias, não restaria outra alternativa, senão construir sua primeira casa utilizando, basicamente, matéria-prima retirada da própria floresta. Estas e outras necessidades proporcionaram, especialmente nos primeiros tempos, uma circunstancial aproximação com a população cabocla. O modelo implantado era totalmente inspirado nas residências destes lavradores nacionais da região. O tipo primitivo da casa do colono deixava muito a desejar, e este era o retrato da vida sem privilégios a que estavam sujeitos.

As palmeiras forneciam quase toda matéria-prima necessária à confecção da casa primitiva: os troncos partidos e ligados por cipó formavam as paredes; as folhas entrelaçadas e amarradas às ripas, serviam de teto. Uma amarração de paus e cipó encostada a uma das paredes substituía o leito. Troncos de árvores e caixotes substituíam a falta de cadeiras e mesas (FERRAZ, 1950, p. 151). Os ranchos consistiam em quatro postes que sustentavam um telhado de folhas de palmeira. Os currais para porcos e gado também eram feitos, como entre os caboclos, com varas de bambu ou palmito, ou estacas fincadas de modo a oferecer proteção contra a chuva. $\mathrm{O}$ interior da "casa" era dividido em dois ou três cômodos. Um deles era a cozinha e a sala de estar onde havia um fogão aberto. Simples aberturas sem vidraças, mas fecháveis, serviam para ventilação. A choupana era feita rusticamente, e o chão batido substituía o assoalho (FERRAZ, 1950, p. 151).

Com o crescimento econômico, os colonos passam a construir casas que vão se diferenciando dos ranchos de caboclos. As habitações passam a ser mais confortáveis, evidenciando suas experiências, cultura e tradições da terra de origem. Neste momento, o material de construção para casa e rancho já eram tabuas cortadas na serraria. Agora tratava-se de uma casa de madeira bem feita e construída sobre pilares. A área era retangular e de 30 a 40 metros quadrados, o chão era assoalhado. O telhado era puxado 
para trás, cobrindo geralmente a cozinha. A chaminé de tijolos era levantada no lado de fora da cozinha (FERRAZ, 1950, p. 151).

Foi apenas numa terceira etapa do desenvolvimento econômico que os colonos chegaram ao modelo de habitação que melhor combinou os traços europeus com alguns novos adotados na nova pátria. "A casa de tijolos com madeiramento a mostra, tipo enxaimel, com telhado puxado para frente para cobrir uma varanda, janelas com vidraças e chão assoalho. A casa de madeira antiga continua, não raro ao lado da construção mais recente e serve de cozinha ou paiol" (FERRAZ, 1950, p. 215).

A distribuição espacial de cada lote colonial, apresentada no desenho abaixo, refletia a multiplicidade das atividades rurais dos colonos. A necessidade de ajustar o espaço à atividade policultora e à criação de animais fizeram com que cada propriedade possuísse seus espaços bem demarcados. Em sua maioria, as partes fundamentais estavam assim distribuídas: a casa ficava próxima de riachos e da estrada; os ranchos ficavam aos fundos e abrigava a oficina, um depósito para os utensílios agrícolas e os estábulos. Ao lado da casa ainda estavam um galinheiro, uma horta, um pomar, um chiqueiro e outras criações domésticas. Mais afastados ficavam as pastagens cercadas para cavalos e vacas, assim como os diversos cultivos, geralmente compostos pelo canavial e as roças de milho, feijão, mandioca, batata e arroz.

Figura 4: Estrutura da pequena propriedade rural colonial

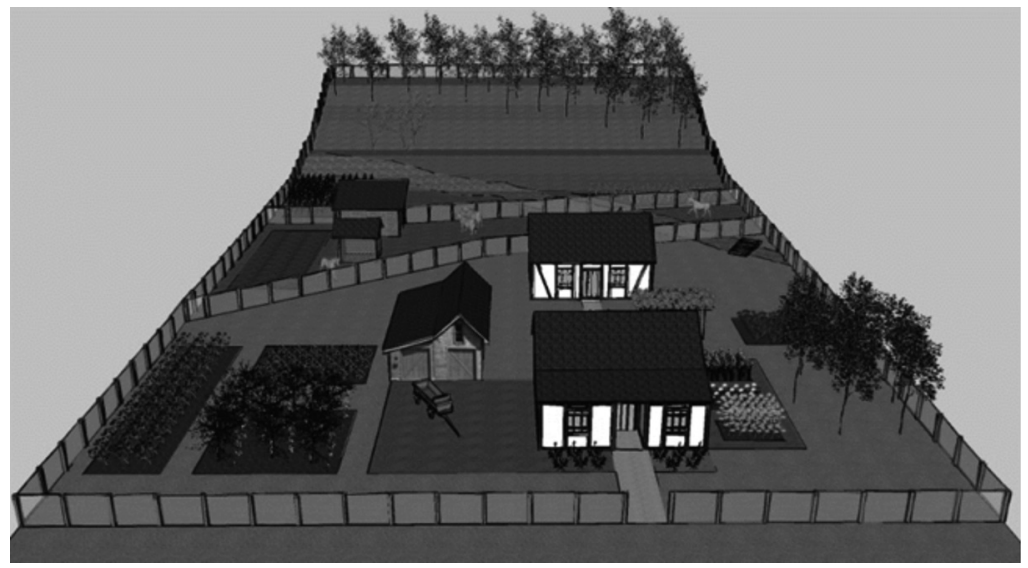

Fonte: Desenho da Arq. Anamaria P. R. Teixeira dos Santos, baseado em croqui de Teobaldo Jamundá In: Centenário de Blumenau 1850 - 2 de setembro - 1950. Blumenau: Edição da Comissão de Festejos, 1950. 
Esta forma de divisão do espaço dentro de uma propriedade rural colonial prevaleceu durante muitos anos, e ainda hoje é possível observar sua presença nos distritos rurais das antigas colônias. Mesmo com áreas cada vez mais fragmentadas, proporcionando propriedades cada vez mais inviáveis economicamente, o modelo de distribuição dos lotes também permanece com o sentido longitudinal em relação às estradas.

A lida rural era caracterizada pelo trabalho familiar. As famílias numerosas representavam mais braços para o trabalho. Assim afirma Paulo Lago:

A família extensa era ideal, compatibilizando-se com as funções da propriedade rural, policultora e poliprocessadora de matérias-primas. As operações seriam, como se procurou, diversificadas. Havia lavouras para se cuidar, animais para criar, tratar, ordenhar, alimentar; havia argila para fabricação de tijolos, madeira para serrar e para manipulação de equipamentos, utensílios, cercas, construção de patrimônio, abrigo de produtos vegetais e animais, casas, estábulos e pontes. Havia matérias-primas para fabricação de queijo, manteiga, creme, embutidos de carne, farinhas, enfim, serviços que implicavam a participação familiar, de homens, mulheres, crianças, em grande número. Nas colônias, a mão-de-obra não comportava escravos nem assalariados (1988, p. 88).

As virtudes de uma família numerosa estavam condicionadas à manutenção da produtividade da terra. Nos primeiros anos, a fertilidade da terra logo após a derrubada da mata proporcionava altos níveis de produtividade. Entretanto, esta alta produção, que inicialmente deslumbrava os colonos, apresentou forte redução em tempo mais curto do que imaginavam. O uso intensivo das terras pelo sistema de derrubada e queimada não era compatível com o tamanho dos lotes coloniais.

As resistências ambientais, nem sempre perceptíveis, acabam surgindo, surpreendendo agricultores experientes, mas de outros ambientes regidos por mecanismos distintos dos trópicos. O tamanho ideal da propriedade era imaginado sob a lógica de ambientes de clima temperado de chuvas pouco insistentes, de superfícies menos enérgicas. O que surpreendeu foi a velocidade do exaurimento de solos que pareciam apresentar excepcionais qualidades (LAGO, 1988, p. 88).

Os problemas com o tamanho da propriedade familiar estavam, portanto, diretamente relacionados as técnicas e procedimentos de uso da terra no clima tropical.

O tamanho ideal de uma propriedade não é somente uma questão de grandeza espacial. Sua adequação depende de condições mais externas, naturais e sócio-econômicas-culturais. Sob tais influências, o tamanho de uma propriedade pode ser tanto excessivo quando ínfimo. Será ideal, mas sob circunstâncias muito especiais (FERRAZ, 1950, p. 216). 


\section{Considerações finais}

Portanto, a implantação de colônias de imigrantes no sul do Brasil resultou em significativas transformações ambientais, econômicas e culturais, mas esteve distante de atingir muitos dos objetivos idealizados por seus incentivadores. A colonização europeia não proporcionou ao meio rural brasileiro os avanços técnicos esperados. Além disso, o processo de privatização das terras, consideradas vazios demográficos pelo poder público, efetivou o processo de exclusão dos lavradores nacionais e das populações indígenas. Ainda assim, mesmo sem grande parte dos resultados imaginados, este processo de colonização foi responsável pela construção de um novo espaço rural, baseado na pequena propriedade e com um modelo de ocupação que ainda pode ser identificado nas diversas partes do sul do Brasil.

\section{Referências}

ABRANTES, Visconde de. Memória sobre os meios de promover a colonização. Revista de Imigração e Colonização, ano II, n. 2-3, 1941.

BLOCH, Marc. A terra e seus homens: agricultura e vida rural no Século XVII e XVIII. São Paulo: Edusc, 2001.

BOSERUP, Ester. Evolução agrária e pressão demográfica. Estudos Rurais. São Paulo: Hucitec/Polis, 1987.

CARDOSO, Ciro Flamarion. Agricultura, escravidão e capitalismo. Petrópolis: Vozes, 1979.

DEAN, Warren. A Ferro e Fogo: a história e a devastação da Mata Atlântica brasileira. São Paulo: Companhia das Letras, 1996.

DUARTE, Regina Horta. História e natureza. Belo Horizonte: Autêntica, 2005.

FERRAZ, Paulo Malta. Como viviam os primeiros colonos. In: Centenário de Blumenau 1850 - 2 de setembro - 1950. Blumenau: Edição da Comissão de Festejos, 1950.

HILLESHEIM, Anselmo Antônio. O crescimento do mercado interno numa colônia do Império - O caso de Blumenau: 1850-1880. (Parte 2). In: Revista Blumenau em Cadernos - Tomo XLI - n. 6, jun. 2000.

HILLESHEIM, Anselmo Antônio. O crescimento do mercado interno numa colônia do Império - O caso de Blumenau: 1850-1880. (Parte 1). Revista Blumenau em Cadernos - Tomo XLI, n. 5, maio, 2000.

KEITH, Thomas. O homem e o mundo natural. São Paulo Companhia das Letras, 2001, p. 17. 
KLUG, João. Propostas para a agricultura no início do Império: um estudo comparativo entre as ideias de Friedrich von Weech e Carlos Augusto Taunay. História: Debates e Tendências, Passo Fundo, v. 1, n.1, p. 21-35, jun. 2009.

LAGO, Paulo Fernado. Gente da Terra Catarinense: desenvolvimento e educação ambiental. Florianópolis: Ed. da UFSC/FCC Edições /Ed. Lunardelli/UDESC, 1988.

LINHARES, Maria Yedda. História Agrária. In: CARDOSO, Ciro Flamarion. Domínios da História. Rio de Janeiro: Campus, 1997.

LINHARES, Maria Yedda; SILVA, Francisco Carlos Teixeira. A história da agricultura brasileira: debates e controvérsias. São Paulo: Brasiliense, 1981.

RICHTER, Klaus. A Sociedade Colonizadora Hanseatica de 1897 e a colonização no interior de Joinville e Blumenau. Florianópolis: Ed. da UFSC; Blumenau: Ed. da FURB, 1986.

MACHADO, Paulo Pinheiro. A Politica de Colonização do Império. Porto Alegre: Editora da Universidade/UFRGS, 1999.

MAZOYER, Marcel; ROUDART, Laurence. História das agriculturas no mundo: do neolítico à crise contemporânea. São Paulo: Editora da UNESP; Brasília, DF: NEAD, 2010.

PESSANHA NEVES, Delma. A agricultura familiar e o Claudicante Quadro Institucional. In: LOPES, S. A.; MOTA, D. M. da; MAGNO DA SILVA, T. E. (Orgs.). Ensaios: desenvolvimento e transformação na agricultura. EMBRAPA, 2002, p. 143-144.

SANTOS, Milton. Metamorfoses do espaço habitado. São Paulo: Hucitec, 1997.

SCHAMA, Simon. Paisagem e memória. São Paulo: Companhia das Letras, 1996.

SEYFERTH, Giralda. Imigração e cultura no Brasil. Brasília: Editora da UNB, 1990.

SEYFERTH, Giralda. Imigração, colonização e estrutura agrária. In: WOORTMANN, Ellen F. (Org.). Significados da Terra. Brasília: Editora Universidade de Brasília, 2004, p. 69-150.

SILVA, José Ferreira da. História de Blumenau. Florianópolis: Editora Empreendimentos Educacionais Ltda., 1972.

WOORTAMNN, Ellen F. (Org.). Significados da Terra. Brasília: Editora Universidade de Brasília, 2004.

ZARTH, Paulo Afonso. Do arcaico ao moderno: o Rio Grande do Sul Agrário do século XIX. Ijuí: Editora Unijuí, 2002. 